\title{
Design of a New Type of Mechanical Mechanism Demonstration Teaching Aid
}

\author{
Haiting Zhang, ${ }^{1, a}$, Caixiao $\mathrm{Gu}^{1, \mathrm{a}}$, Jianbo Cao ${ }^{1, \mathrm{~b} *}$, Jianxia Cao ${ }^{2, \mathrm{~b}}$,Tianfeng Zhao ${ }^{3, \mathrm{~b}}$, \\ Yanger Shi ${ }^{1, a}$ and Shiju $E^{1, b}$ \\ ${ }^{1}$ College of Engineering, Zhejiang Normal University, Jinhua, Zhejiang 321004, P.R. China \\ ${ }^{2}$ Jinan Jindingnuo Pump Co., Ltd, Jinan, Shandong 250100, P.R. China \\ ${ }^{3}$ Library, Zhejiang Normal University, Jinhua, Zhejiang 321004, P.R. China \\ a1023075344@qq.com, ${ }^{\text {b*} C o r r e s p o n d i n g ~ a u t h o r: ~ c a o j i a n b o 2008 @ 163 . c o m ~}$
}

\begin{abstract}
Keywords: Mechanical structure, Teaching aids, Linkage control, Time delay
Abstract. In order to solve the problem of mechanical professional courses classroom boring, designed a new interest linkage mechanical mechanism demonstration teaching aid. The teaching aid comprises five sets of mechanical mechanism, respectively, gear mechanism, Geneva mechanism, slider crank mechanism, an eccentric wheel mechanism and a crank rocker mechanism, the linkage mechanism device to run a series of each mechanism are mounted in a plastic box, the demonstration started general switching power supply, the small ball rolling into the box through the rubber hose, connected circuit, the electromagnetic lock electric lock indent, frame and a mechanism that plate falling, plate engraved with the mechanism of description, teaching effect. The plate falling touch stroke switch, the motor power, operation mechanism, for each mechanism are equipped with relay, so after a period of time will make the organization a power operation, in the same way, until finally a mechanism. The teaching aid has strong interest, is beautiful and practical, easy to use, and has good practical value.
\end{abstract}

\section{Introduction}

With the rapid development of science and technology, new technology, new materials are constantly emerging, especially with the development of information technology, as carry out the self-made teaching aids activities provides a new stage and conditions. And domestic provinces and cities, are held all kinds of self-made teaching competition. The emergence of a series of important results, but in the actual teaching process, with the current curriculum reform, the development of mechanical teaching in teachers and equipment, can not meet the need, in addition, Europe and other developed countries, attaches great importance to the development and use of the self-made teaching aids. Schools at all levels to use a large number of aids, and encourage students to explore the development of new materials.

And the mechanical structure of the study is to learn the key mechanical professional, Through the teacher's explanation and students practice, students are not easy to understand and remember. The typical mechanism of mechanical structure of self-made teaching aids teaching requirements and low cost and devoted to the theory and practice of teaching [1-3], teaching with multimedia display, in addition to the motion of the mechanism, the teachers may aid teaching to enhance the students knowledge of theory and understanding, to stimulate students interest in learning [4-6]. The design of the 5 sets of common mechanism is made into a new mechanical demonstrator. Through the establishment of the linkage mechanism to Classroom fun. And the realization of the delay and the automatic running function, high safety and reliability, simple operation.

\section{Main Performance of New Mechanical Mechanism Demonstration Teaching Aid}

\section{(1) High interest}

The work adopts a linkage, the total circuit connected to the ball drop mechanism, electromagnetic lock electric lock indent, which stand on the whereabouts of that board, display mechanism, add interest to the whole set of device. 
(2) The teaching effect is good

Mechanism of operation, organization frame and the electromagnetic lock is fixed, written on the board of the agency's introduction, organization, and combining the teaching material illustration board.

(3) Adjustable delay time, realize the linkage

After operation, four mechanism controlled by relay and a travel switch respectively, and the adjustable delay circuit, stable, realize the linkage.

\section{Design Schemes}

Overall Design of Device. The whole device is composed of several can be stacked boxes, the overall volume of not more than $1.2 \times 1.2 \times 1.2 \mathrm{~m}$, The single block mechanism demonstration board $290 \times 320 \mathrm{~mm}$, The whole device is a total length of 1.5 meters, Device includes the design into three parts:

A total of 5 institutions demo board, respectively for the gear mechanism, Geneva mechanism, crank rocker mechanism, slider crank mechanism, an eccentric wheel mechanism; mechanism of the plate with light weight, good appearance of the acrylic plate making, the mechanism of the board; mechanism of storage box, choose light, high strength engineering plastics plate production. A total of 6 boxes, 5 placing mechanism, the 1 placed appliances. The box is provided with a handle and a bandage, the bottom bracket, bracket can be disassembled, easy to carry.

The mechanism box is as shown in Fig. 1 .

Circuit Design. In order to have enough torque, the motor of each mechanism are use of worm gear motor to drive mechanism. Rated voltage of the motor $U=12 \mathrm{~V}, I=0.3 \mathrm{~A}$, speed $n=16 \mathrm{r} / \mathrm{min}$. Delay control with time delay relay, voltage relay $12 \mathrm{~V}$, model AH3-3, a group of instantaneous center of another group delay. In order to stabilize the voltage, the voltage source $12 \mathrm{~V}$, rated power $36 \mathrm{~W}$.

The mechanism box between the circuit in parallel, using $12 \mathrm{~V}$ source control voltage regulator.

The circuit diagram of a mechanism box is as shown in Fig. 2.

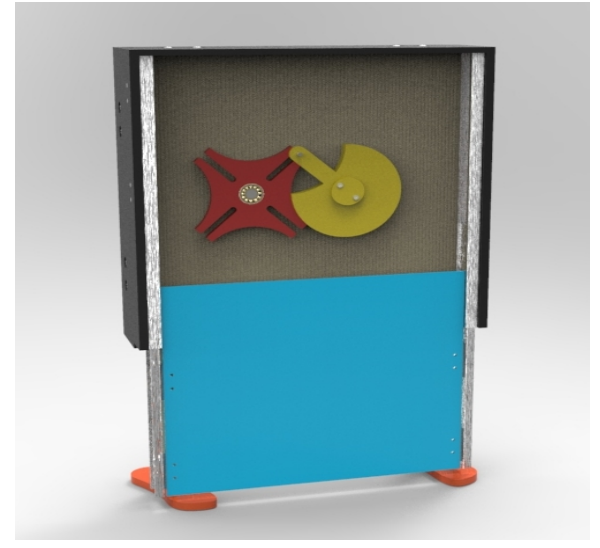

Fig. 1 The mechanism box

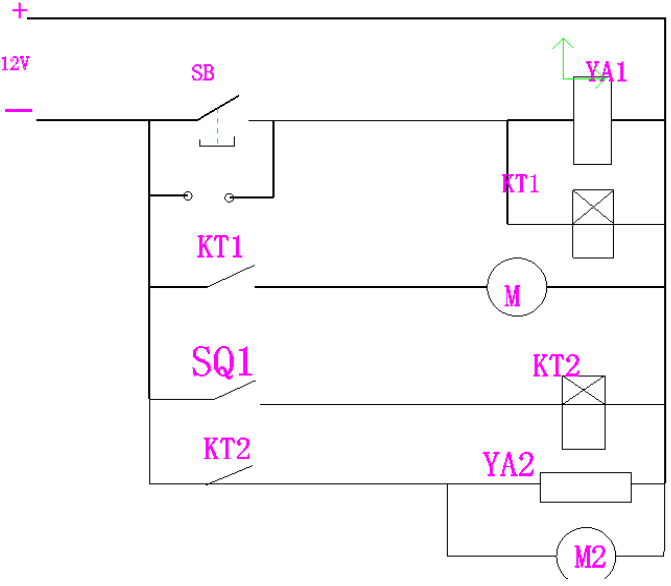

Fig. 2 Schematic diagram of the circuit

\section{Working Principle and Performance Analysis}

Basic Principle of Mechanical Mechanism. Gear mechanism: adopted planet gear mechanism. The outer diameter of ring gear selection $106 \mathrm{~mm}$, diameter $91 \mathrm{~mm}$. The number of teeth $81 \mathrm{~mm}$. The center gear: $45 \mathrm{~mm}$, gear $18 \mathrm{~mm}$, diameter $15 \mathrm{~mm}$. Gear: tooth number 31 , outer diameter $38 \mathrm{~mm}$, inner diameter of $8 \mathrm{~mm}$.

Connected to the planet gear center gear and shaft by keys, by outer ring gear ring is fixed on the outer sleeve body plate, axle center wheel is connected with a belt pulley. When the demonstration, 
motor power of the planetary gear to rotate, the outer gear ring of the planetary wheel is driven to rotate the pulley. The belt drive is set to 1.5 .

Performance analysis: the use of belt pulley to drive the rotating planetary gear mechanism, making the work smoothly, the required torque is small.

The planetary gear mechanism is shown in Fig. 3.

Geneva Mechanism: A relatively simple structure of the single arm outer grooved sheave is selected,it consists of active wheel, driven wheel and frame. Angle of Geneva mechanism $\varphi_{0}=45^{\circ}$,

Slot number $Z=4$, Dial diameter $d=100 \mathrm{~mm}$, dial through a shaft connected with the motor, in order to reduce friction, grooved wheel center hole of shaft and the shaft are in interference fit with.

Performance analysis: single arm external grooved wheel mechanism, has the advantages of simple structure, easy processing, reliable work.

Geneva mechanism is shown in Fig. 4.

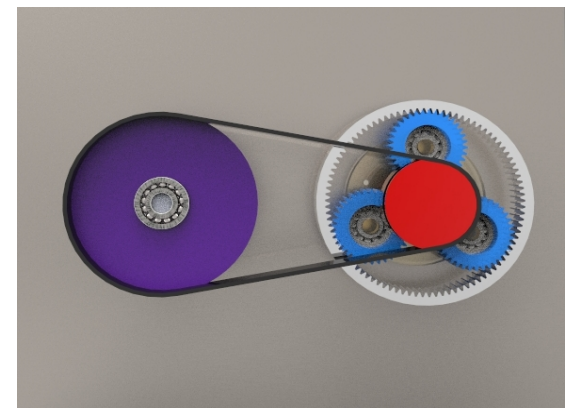

Fig. 3 The planetary gear mechanism

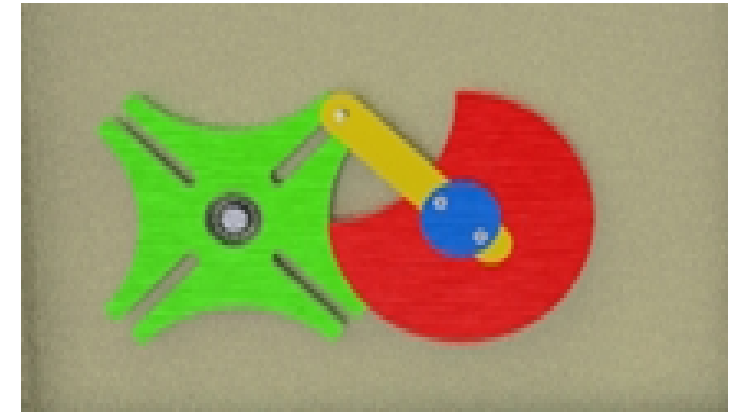

Fig. 4 The Geneva mechanism

Slider crank mechanism: Demonstration of pressing machine model is used as a slider crank mechanism. Pressing machine pressure in the bag for the slider member, Through the component at the top of the crank and slider for connecting rod, The motor is connected with the rotating rod, the motor rotates to drive the rotating rod, so that the slider to move up and down.

Performance analysis: slider crank mechanism to achieve linear motion is relatively simple, for wear resistance, high flatness.

Pressing machine model is shown in Fig. 5

The eccentric wheel, the eccentric mechanism is a cam mechanism. Also known as the eccentric cam. When running, the motor drives the rotation of the eccentric wheel, and the eccentric wheel drives the frame about translation, for reciprocating motion. The eccentric shaft is connected with the motor through the frame through two fixed bracket is fixed on the board, mechanism. The eccentric wheel diameter $\mathrm{D}=80 \mathrm{~mm}$, eccentricity $l=15 \mathrm{~mm}$, the biggest rise $L=30 \mathrm{~mm}$.

Performance analysis: stable operation, good abrasion resistance material.

Eccentric mechanism is shown in Fig. 6.

Crank and rocker mechanism: use the component of planar four bar mechanism, set up the original shape. Operation mechanism, a plurality of rod rotation by the driving shaft and drive.

Crank and rocker mechanism is shown in Fig. 7.

Design Principle of Time Delay Control System. New type of linkage mechanism. The slide show presentation aids in the form of landing, considering the display plate falling process on mechanical mechanism of the delay requirements of high, the time delay relay and a travel switch is now commonly used in. Relay type AH3-3, a group of instantaneous, another group delay, delay time adjustable. Travel switch the switch switches, touch switches from the plate.

In order to ensure the safety of the power switch circuit, selection of the air switch. Demonstration at the beginning of the first press the power switch, the small steel ball falling from plastic pipe, connected circuit, electromagnetic lock lock indent body energized, display plate falling, touch switch, the mechanical mechanism of running. Mechanism of time delay control, a mechanism through the time delay relay cycles, until finally a mechanism. 
Performance analysis: stable circuit, delay control mechanism, linkage, providing interesting mechanism.
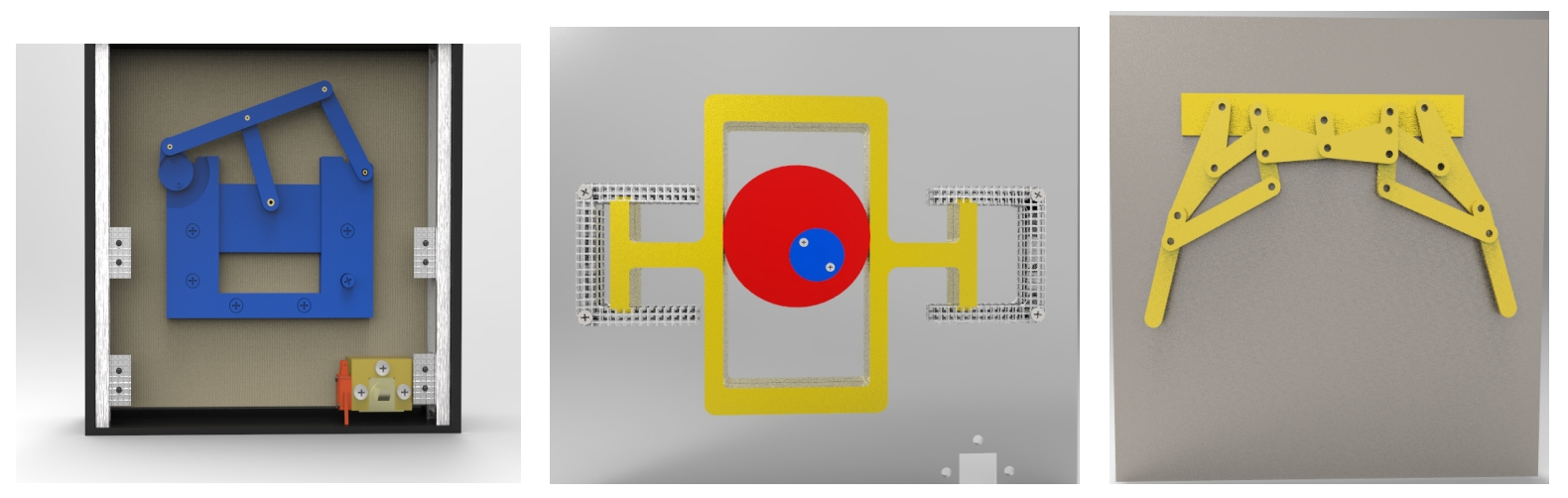

Fig. 5 Slider crank mechanism Fig. 6 An eccentric wheel mechanism Fig. 7 Crank rocker mechanism

\section{Innovation and Application}

The new mechanism demonstration teaching aid the design work, the main innovative points include:

(1) Achieve the linkage mechanism, and through the relay delay control, high interest.

(2) Has described the panel, the teaching effect is good.

(3) Has the advantages of simple operation, high efficiency and convenient.

(4) Portable, economical and practical.

\section{Conclusion}

In this paper, the shape and size of the new materials and the mechanical mechanism of demonstration teaching aid for the design and research, and draw a new mechanical demonstrator effect drawing and assembly drawing with UG software. Mechanism of demonstration teaching aid with delay and automatic operation, high safety and reliability, simple operation, strong interest, to students learning convenience and other advantages, will be of great practical value and good social benefits.

\section{Acknowledgement}

The work was supported by the National Natural Science Foundation of China (No. 51377146, 51407162), Zhejiang Provincial Natural Science Foundation of China (No. LQ13E050009), the 2013 Foundation of Education Department of Zhejiang Province of China (No. Y201329556), the Development Project of Zhejiang Normal University Student From Poor Family, Qiutian Fund of College of Engineering, Zhejiang Normal University.

\section{References}

[1] Y.G. Song: The Youth and Society: a Study of Education in China and Foreign Countries, (2011) No. 11, pp. 23.

[2] C.H. Wang, S. Wang and J. Xiong: Education Forum, (2013) No. 39, pp. 54-55.

[3] Y.H. Wu: Occupation, (2011) No. 20, pp. 169-170.

[4] X.B. Wang and Y.K. Qin: Journal of Henan Mechanical and Electrical Engineering College, (2012) No. 1, pp. 6-7.

[5] F.L. Gui, S.Q. Liu, L.H. Li and D. Li: Journal of Zhejiang Normal University (Natural Sciences), Vol. 38 (2015) No. 1, pp. 52-57.

[6] Y.G. Song: The Youth and Society: a Study of Education in China and Foreign Countries, (2011) No. 10, pp. 122. 